\title{
Improving Cow Fertility Through Fish Meal Supplementation $\mathbf{1}$
}

\author{
Charles R. Staples, Richardo Mattos, Carlos S. Risco and William W. Thatcher ${ }^{2}$
}

\section{Introduction}

A goal on most dairy farms is to keep the interval between the time a cow calves and the time she becomes pregnant again as short as possible. Keeping this time interval short, however, is opposed by the high nutritional demands of lactation. The energy required for milk production usually exceeds the energy eaten by the cow in the first couple of months after freshening. Therefore, the cow must rely on the energy stored in her body as fat to help support her milk production. This condition, called negative energy status, can force cows to delay their return to estrus until their diet supplies more and more of their energy requirement. If the negative energy state is severe or prolonged, the number of days open can be excessive and costly.

In order to help cows cope with this situation, fats are often added to the diet in order to increase the energy density of the diet. Tallow contains 2.25 times more net energy than ground corn. Fat supplementation has had some surprising results. However, supplemental fat often has not reduced the cow's negative energy status as planned. Why not?
Milk production is often improved and feed intake is often decreased. As a result, energy output still exceeds energy intake. Nevertheless, fat supplementation has improved pregnancy rate in several experiments. In fact, some herds went into a more negative energy balance when fed supplemental fat and yet still managed to demonstrate greater fertility. If fat supplements are not improving the energy status of cows, then what is responsible for improved fertility? Recent research suggests that particular fatty acids found in some fats are responsible for improved reproductive performance.

Fats contain many different fatty acids. Each fatty acid has it own unique structure that allows it to act differently within the animal. A group of fatty acids called polyunsaturated fatty acids are of special interest in this discussion. Polyunsaturated fatty acids are thought to be of particular health benefit in the human diet. Individual fatty acids in this group are linoleic acid, linolenic acid, eicosapentaenoic acid (abbreviated EPA), and docosahexaenoic acid (abbreviated DHA). When fats containing these fatty acids were fed to lactating dairy cows in university experiments, reproductive performance was often

1. This document is DS-95, one of a series of the Animal Sciences Department, Florida Cooperative Extension Service, Institute of Food and Agricultural Sciences, University of Florida. Original publication date February 7, 2002. Revised July 19, 2005. Visit the EDIS Web Site at http://edis.ifas.ufl.edu.

2. Charles R. Staples, professor of nutrition; Ricardo Mattos, dairy reproductive physiologist, Monsanto Co.; Carlos S. Risco, associate professor of large animal clinical sciences; and William W. Thatcher, graduate research professor of reproduction, retired; Cooperative Extension Service, Institute of Food and Agricultural Sciences, University of Florida, Gainesville, 32611.

The Institute of Food and Agricultural Sciences (IFAS) is an Equal Opportunity Institution authorized to provide research, educational information and other services only to individuals and institutions that function with non-discrimination with respect to race, creed, color, religion, age, disability, sex, sexual orientation, marital status, national origin, political opinions or affiliations. U.S. Department of Agriculture, Cooperative Extension Service, University of Florida, IFAS, Florida A. \& M. University Cooperative Extension Program, and Boards of County Commissioners Cooperating. Larry Arrington, Dean 
improved. In 11 of 17 studies published in scientific journals since 1988, either first service pregnancy rate or overall conception/pregnancy rate was improved when cows received supplemental fat.

\section{Fat Sources}

Fat supplements that have improved fertilityof lactating dairy cows include fish meal, tallow, and calcium soaps of palm oil. Fish meal is a good source of EPA and DHA fatty acids whereas the other fats contain linoleic acid. Normally when polyunsaturated fatty acids are fed to cows, microorganisms in the rumen will change most of them to saturated fatty acids. Saturated fatty acids are thought to have less or no effect on reproductive processes. However, EPA and DHA fatty acids are more resistant to ruminal microorganisms than are the fatty acids found in vegetable sources. More EPA and DHA escape the rumen as polyunsaturated fatty acids and travel to the small intestine where they are absorbed to have their effect on reproduction.

\section{Effects of Feeding Fish Meal on Reproduction of Lactating Dairy Cows}

Fish meal is rich both in fat (8.4\%) and in ruminally undegradable protein. The fish meal made from menhaden fish contains EPA at $11.6 \%$ of the fat and DHA at $6.6 \%$ of the fat. Feeding fish meal to cows during the early postpartum period has improved fertility in several studies. Each of the studies is described in some detail in the following paragraphs and summarized in Figure 1.

Eighty British Friesian cows in Ireland were fed ryegrass silage ad libitum that was supplemented with a concentrate made up mainly of barley and soya-bean meal. Fish meal was fed at a rate of either 0 or 800 grams $(1.8 \mathrm{lb})$ per cow per day.

Supplementation with fish meal improved conception rates from $44 \%$ to $64 \%$ and reduced the number of services per conception from 2.31 to 1.62 .

In Israel, 240 Holstein cows were fed a total mixed ration of approximately $22.5 \%$ forage, $13 \%$ whole cottonseeds, and $64.5 \%$ concentrate. Diets were formulated to $21.6 \%$ crude protein with the main protein feedstuffs being either soya-bean meal

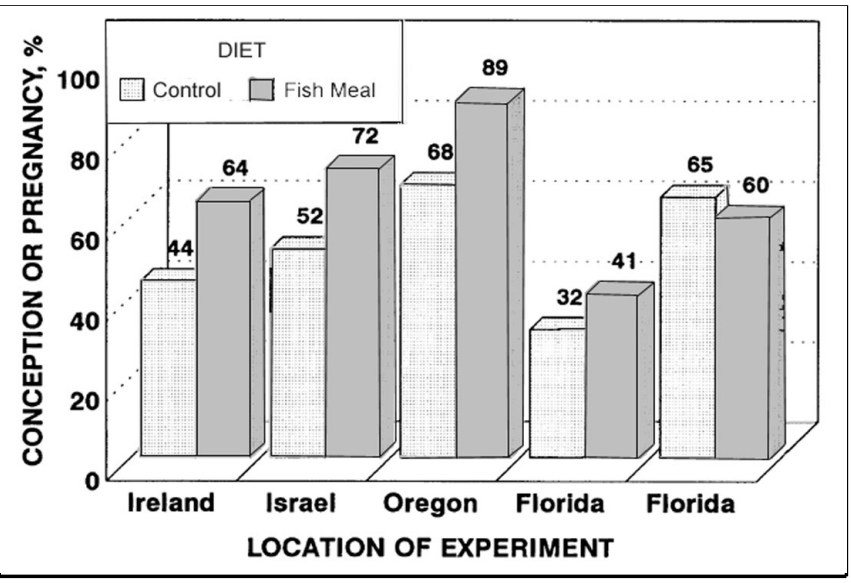

Figure 1. Improvements in conception or pregnancy rates when fish meal was fed to lactating Holstein cows in five separate experiments.

(13.2\% of diet dry matter) or white fish meal from Denmark (7.3\% of diet dry matter). Sixteen weeks after parturition, cows fed the white fish meal had greater pregnancy rates than those fed the soya-bean meal ( $72 \%$ vs. $52 \%)$.

Two of three studies in the United States reported positive effects of feeding fish meal made from menhaden fish. In an Orgeon study involving 44 Holstein cows housed in free stall facilities, diets contained either 0 or $3.5 \%$ fish meal with the fish meal partially replacing soybean meal. Conception rate at first insemination was $89 \%$ for cows fed fish meal compared to $68 \%$ for cows fed no fish meal. However, by 125 days postpartum, pregnancy rates were not different between the two groups ( 84 and $86 \%$ ). Two commerical dairies participated in a study in Florida. Menhaden fish meal replaced blood meal and meat and bone meal on one farm involving 341 Holstein cows. On a second farm involving 300 Holstein cows, menhaden fish meal replaced corn gluten meal, blood meal, and meat and bone meal. At approximately 51 days postpartum, all cows were synchronized to estrus for the first breeding. By 120 days postpartum, pregnancy rates were similar between cows fed the control and fish meal diets (65 versus $60 \%$ ) at the first dairy farm. However, at the second dairy farm, cows fed fish meal had improved pregnancy rates of $41 \%$ compared to $32 \%$ for cows fed the other protein sources. 


\section{How Fish Meal May Work To Improve Fertility}

Recent studies show that the fatty acids in fish meal can influence the important reproductive hormone, prostaglandin $\mathrm{F}_{2 \text {-alpha }}\left(\mathrm{PGF}_{2 \text {-alpha }}\right)$. Upon delivery of the calf, the uterus produces $\mathrm{PGF}_{\text {2alpha }}$ in large quantities. The $\mathrm{PGF}_{2 \text {-alpha }}$ contributes to the process of causing the uterus to shrink back to its prepregnant size. In addition, the corpus luteum which has been maintained on the ovary during the last nine months is further regressed by $\mathrm{PGF}_{2 \text {-alpha }}$. The uterus continues to be responsible for secreting $\mathrm{PGF}_{2 \text {-alpha }}$ at the end of each estrous cycle to regress the corpus luteum if the cow is not pregnant. So prostaglandins play an important role in re-establishing estrous cycles both immediately after parturition and thereafter until conception occurs.

When the cow does conceive, the newly formed embryo signals the cow that it exists at about day 17 of the estrous cycle so that the uterus does not release $\mathrm{PGF}_{2 \text {-alpha }}$. This keeps the corpus luteum active and producing the hormone progesterone. As long as the corpus luteum is producing progesterone, the cow remains pregnant. High concentrations of progesterone in the blood or milk for three weeks usually indicate that the cow is pregnant.

How might EPA, DHA, and linoleic acid influence these events in order to improve the chance of pregnancy? As an embryo is created, these fatty acids can assist in its preservation by reducing the synthesis of $\mathrm{PGF}_{2 \text {-alpha }}$ from the uterus. Studies conducted at the University of Florida demonstrated that lactating dairy cows fed fish meal at $2.7 \%$ of diet dry matter released dramatically less $\mathrm{PGF}_{2 \text {-alpha }}$ when stimulated by an injection of oxytocin. Approximately $40 \%$ of the cows that conceive lose their embryos between eight and 17 days of pregnancy. If these fats are in the diet, the life of the corpus luteum may be prolonged at conception and early embryonic death prevented. At the Florida dairy farm mentioned earlier where diets containing fish meal stimulated prgnancy rates, a smaller proportion of the cows fed fish meal fully regressed their corpus luteum at 48 hours after an injection of $\mathrm{PGF}_{\text {2-alpha }}$ based upon blood progesterone concentrations (Figure 2). This may have resulted from the fish oils inhibiting synthesis of $\mathrm{PGF}_{2 \text { alpha }}$ by the uterus.

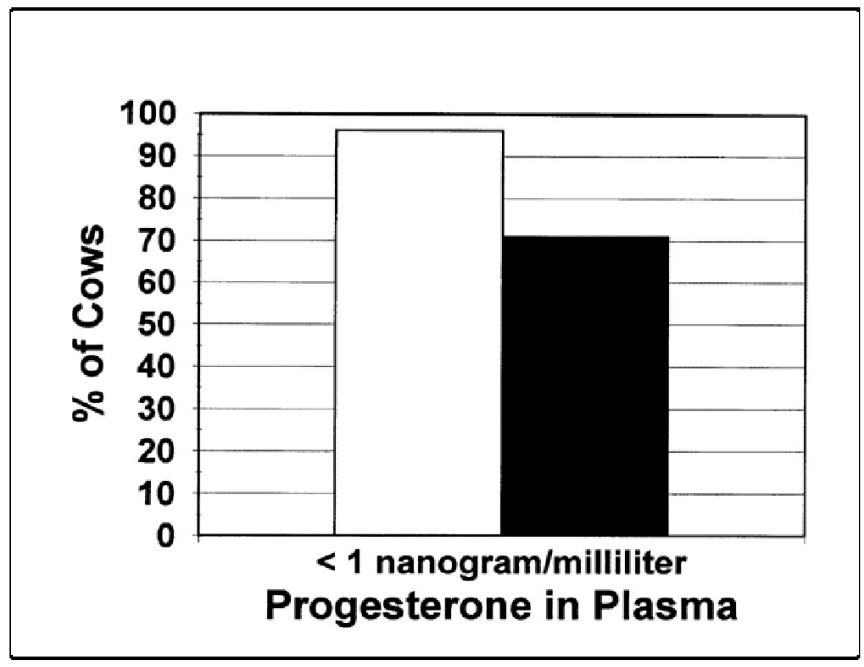

Figure 2. Full regression of the corpus luteum (defined as less than 1 nanogram of progesterone per milliliter of blood plasma) at 48 hours after an injection of PGF occurred in fewer lactating dairy cows fed menhaden fish meal at a Florida dairy farm. Twenty-four out of 25 cows (96\%) fed a $0 \%$ fish meal diet (white box) regressed their corpus luteum normally compared with 22 out of 31 (71\%) cows fed a diet of $2.8 \%$ menhaden fish meal (black box).

This mode of action by fish oils is similar to what happens naturally to preserve the life of the embryo. The endometrium tissue of the uterus in the newly pregnant cow contains more of the polyunsaturated fatty acid, linoleic acid, than a nonpregnant cow. Linoleic acid may act to block the synthesis of $\mathrm{PGF}_{2 \text {-alpha }}$ by the uterus. The additional supply of these important fatty acids in the diet may aid in this process, thus preserving a pregnancy in its earliest day (Figure 3).

Situations may exist in which dietary fish meal may be of particular benefit. Theoretically, cows under heat-stressed conditions may particularly benefit from this diet because cows produce more $\mathrm{PGF}_{\text {2-alpha }}$ during heat stress, although this has not been tested. Secondly, fish meal may have a greater impact on fertility when fed to cows having little access to pasture. In a grazing situation, the cow consumes small amounts of linolenic acid, a polyunsaturated fatty acid, in the grass. Some linolenic acid will escape saturation in the rumen, pass the small intestine, and be modified to form EPA and DHA. Scientists in the United Kingdom have 


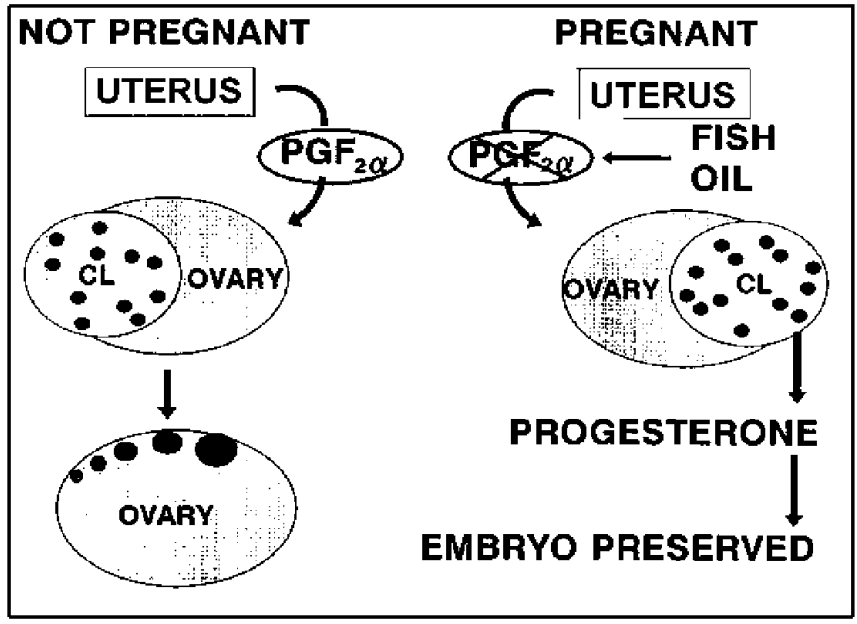

Figure 3. Potential mechanism by which fish meal may improve fertility of lactating dairy cows. If conception does not occur (left side), the uterus secretes PGF 2-alpha $_{\text {at the }}$ end of the estrous cycle to regress the corpus luteum $(C L)$ and recruit a new follicle for another ovulation. If conception does occur (right side), $\mathrm{PGF}_{\text {2-alpha }}$ is not released from the uterus and the $C L$ is maintained on the ovary to produce progesterone to preserve the life of the embryo. Unique fatty acids in fish meal may help suppress synthesis of $\mathrm{PGF}_{\text {2-alpha }}$.

reported that meat from cows fed pasture contains EPA and DHA. Cows being inseminated and consuming pasture may benefit reproductively from the linolenic acid in the grass because of its protential role in suppressing $\mathrm{PGF}_{\text {2-alpha }}$. However, when cows are fed high-concentrate diets, intake of linolenic acid is usually very low. Therefore, supplemental EPA and DHA coming from fish meal may benefit breeding cows fed high-concentrate diets.

\section{Summary}

1. Dairy cows put out more energy in their milk and body processes than they take in through their diet in the first few weeks of lactation. This can be detrimental to good reproductive performance.

2. Fats may be added to diets of lactating dairy cows in order to increase energy intake and therefore milk production. However, energy balance often is not improved because supplemental fat often improves milk production.

3. Nevertheless, fertility has been improved by fat supplementation. Feeds that have improved pregnancy rates include fish meal, tallow, and calcium salts of palm oil.
4. Feeding fish meal as low as $2.8 \%$ of diet dry matter has improved conception and/or pregnancy rates of lactating Holstein cows in experiments done in Ireland, Israel, and the United States.

5. Fish meal contains some unique fatty acids that can partially resist microbial changes in the rumen; these fatty acids may be responsible for improved fertility.

6. These fatty acids may reduce the synthesis of $\mathrm{PGF}_{\text {2-alpha }}$ by the uterus at the time of conception so that the life of the corpus luteum is prolonged and early embryonic death is avoided.

\section{References}

Armstrong, J. D., E. A. Goodall, F. J. Gordon, D. A. Rice, and W. J. McCaughey. 1990. The effects of levels of concentrate offered and inclusion of maize gluten or fish meal in the concentrate on reproductive performance and blood parameters of dairy cows. Anim. Prod. 50:1.

Bruckental, I., D. Drori, M. Kaim, H. Lehrer, and Y. Folman. 1989. Effects of source and level of protein on milk yield and reproductive performance of high-producing primiparous and multiparous cows. Anim. Prod. 48:319.

Burke, J.M., C.R. Staples, C.A. Risco, R.L de la Sota, and W.W. Thatcher. 1997. Effect of ruminant grade menhaden fish meal on reproductive and productive performance of lactating dairy cows. J. Dairy Sci. 80:3386.

Carroll, D.J., F.R. Hossain, and M.R. Keller. 1994. Effect of supplemental fish meal on the lactation and reproductive performance of dairy cows. J. Dairy Sci. 77:3058.

Mattos, R. C., C. R. Staples, J. Williams, A. Amorocho, M. A. McGuire, and W. W. Thatcher. 2002. Uterine, ovarian, and production responses of lactating dairy cows to increasing dietary concentrations of Menhaden fish meal. J. Dairy Sci. 85:755-764. 